\title{
Poesía Epica y Novela: El Episodio de Glaura en La Araucana de Ercilla
}

UANDo publicó José Toribio Medina su edición monumen-
tal de La Araucana, intituló "ilustraciones" sus veinte
disquisiciones sobre la obra y el autor. Y allí dio todo lo que
se podía esperar de un gran erudito formado en la escuela
positivista de Mommsen: antecedentes históricos, fuentes li-
terarias, excursus "a propósito" de la obra, digresiones "al-
rededor" del hombre. Al fin y al cabo, ilustraciones. Es
como si el lector de La Araucana descansara la vista sobre her-
mosos grabados que aclararan el texto con precisiones utilí-
simas. Lo de menos es la calidad intrínseca-literaria o es-
tética-, del poema. Medina es el perfecto exégeta que pudiera
"ilustrar" con igual ciencia y objetividad la crónica más ram-
plona y la epopeya más sublime.

Es tiempo que La Araucana se estudie como humana obra de arte, como la invención difícil de un hombre singular obsedido por su tarea, su mensaje y las exigencias de su público.

En la mente de Ercilla, el libro por escribir se presenta como crónica rimada de los hechos de los españoles en el Arauco. Esto, en 1568, al dar la última mano a esta primera

1 Santiago de Chile, 5 vol., 1910-1918. 
parte antes de entregarla al impresor. En 1578, cuando publica la segunda parte, ya es otra cosa: un poema épico con episodios galantes. $Y$ cuando da a su obra su última forma, en 1589-1590, aparece como obra literaria de género ambiguo, histórico y poético, en loor de Felipe II, por un soldado poeta que tomara parte en una de las guerras más obscuras del reinado. El concepto de la obra no ha sufrido alteraciones esenciales, sino que ha evolucionado; y no desaparece sino que se modifica paulatinamente la tonalidad original fj.jada ya en el primer Canto.

Pues bien, las mismas vacilaciones del autor en su trabajo abren como resquebrajaduras por las cuales nos es lícito divisar el modo de funcionar de su mente en medio de las fuerzas contradictorias que la solicitaban.

El episodio de Glaura acaso presenta el mejor ejemplo de esta rebelión de Ercilla contra su propia rutina y la de su público. Al llegar al fin de su segunda parte no está satisfecho - y lo dice-, siente la necesidad de adornar su narración. E interpola la historia de una mujer araucana ${ }^{2}$ con una torpeza técnica que, por cierto, ha de chocar hoy a toda la crítica "gestaltista". Pero, preguntamos, ¿consiste el valor de una obra en la perfecta adecuación de la forma a la intención clara del autor? ¿O bien resulta su gracia espiritual precisamente del desacuerdo entre una y otra, de una riqueza confusa de valores que pasa de la escueta intención consciente? Lo que nos conmueve es el salto en lo desconocido que da el autor impaciente, rebelde, disonante ante su propia letra. En otros términos, si a La Araucana se la considera únicamente como objeto de arte, bien es verdad que los episodios galantes y las visiones de San Quintín y Lepanto rompen la unidad y la armonía del conjunto; son como manchas en su total aspecto, excrecencias o bien granos de arena en los engranajes de su máquina interior. ${ }^{3}$ Pero si se la considera

2 La interpolación va de la última estrofa del Canto XXVII hasta la estancia 52 del Canto XXVIII, siendo la 53 trabucada por inadvertencia del impresor o por la del autor, ya que debiera seguir lógicamente a la 54.

3 Los historiadores contestarían con razón a los formalistas que los modelos de Ercilla dan muestra también de tal diversidad en la acción y hasta en la tonalidad. 
como obra humana, sus perfecciones cobran su máximo valor cuando se revelan frágiles y quebradizas y sus mismas imperfecciones a veces nos conmueven.

No apliquemos, pues, a Ercilla los criterios modernos, ni los de la escuela positivista, ciega a los valores estéticos, ni los de la escuela "formalista", insensible al calor humano de la creación. ¿La perspectiva del mismo poeta sobre su obra sería la única legítima? Tampoco. No basta el juicio del autor para dar cuenta del valor de su engrendro. Muchas veces le vemos fracasar en sus páginas más escritas, más cuidadas. Sus "aciertos" no nos admiran, pero sí el anhelante errar de su pluma entre la rutina y la invención, entre las tentaciones de la facilidad y las exigencias de su genio, entre trivialidades y sublimidades. Según Goethe, lo mejor del hombre es el temblar. También es el temblar lo mejor de la obra literaria. No tratemos a ésta como objeto inanimado ni como reloj hábilmente montado, sino como cosa vivida, que, por cierto, no existe por sí sola, sino que va integrada a la vez en la vida más íntima del autor y en la vida más misteriosa de una colectividad, especialmente de un público socialmente definido. Al descifrarla, sentimos un nacer y un morir perpetuo, adivinamos afirmaciones y denegaciones, bríos y fatigas, retos y debilidades, siempre la perplejidad y por todas partes extremos. En breve, una obra es estéticamente válida cuando se le oye latir el corazón.

La intervención de Guacolda en la Primera parte (Cantos xiii y xiv) había sido adorno épico, fruto de la larga tradición culta y popular, la de Homero y la del romancero. Recordaba Ercilla confusamente la despedida de Héctor y Andrómaca, ${ }^{4}$ el sueño premonitorio de Doña Alda en Aquisgrán, ${ }^{5}$ etc.

En la Segunda parte ya no resiste Ercilla y reniega de su intención original, que era de excluir a Venus de un relato

Dor ejemplo, La Diana de Montemayor (1561) y El Carlo famoso, poema épico de Luis Zapata (1566).

4 llíada, cuento VI.

5 Romancero general de A. Durán, B.A.E., X, No 400. 
consagrado a Marte. Sucumbiendo ante el encanto de Ariosto, nos cuenta los amores de Tegualda (Cantos xx y xxi) y acude al esquema a la vez clásico y caballeresco de la prueba pública entre los pretendientes a la mano de la princesa. Una importante novedad es la encadenación en este tema con otros tres: la muerte gloriosa del joven esposo, los lamentos de la viuda y su desesperación cuando recorre el campo de batalla buscando el cadáver del amante (cf. el tío de don Beltrán en el famoso romance carolingio) ${ }^{6}$ Precisamente se llama episodio a esta serie lógica de tópicos literarios. Aunque la misma Tegualda le da unidad y verosimilitud relatándolo en primera persona, no duda un momento el lector de su carácter ficticio; sabe que es ornato retórico; y tampoco el poeta intenta ocultar la mano.

Muy diferente es el episodio de Glaura, que es la tercera audacia de Ercilla en el curso de su Araucana y constituye la piedra de toque de su genio épico.

En la base de este relato sin duda viene una experiencia vivida por el mismo Ercilla. En efecto, el poeta aparece como personaje esencial en el nudo y en el desenlace de la intriga. Su héroe es su propio yanacona, su fiel criado. Lejos de presentarse la historia como trozo muy escrito y ejercicio de retórica, salta a la vista su construcción relajada: por ejemplo, explica el autor la prisión de Cariolán después de la liberación de éste, a destiempo, cual "arrepentimiento" de pintor poco sagaz. También notemos cómo surgen inútilmente en el relato la intervención y la muerte violenta del padre de Glaura, las cuales no tienen función orgánica que las pueda legitimar. ¿Cómo se pueden explicar estas dos fallas sino por la torpeza del escritor que no supo descartar hechos, históricos, por cierto, pero incongruentes, en una buena fábula literaria?

Tampoco valdría la hipótesis de que el autor intente dar verosimilitud a lo inverosímil con estos detalles superfluos. No, en aquel tiempo, una intriga plausible no requiere toques ni retoques de autenticidad; sólo se acude a los procedimientos de verosimilitud cuando la ficción es harto mentirosa. ${ }^{7}$

- Ibidem, No 395.

7 Véanse Alfonso López Pinciano (Filosofía antigua poética, 1596) o Juan 
El episodio de Glaura no deja por eso de ser una fábula. En efecto, esta experiencia vivida el autor la va a verter en el molde tradicional del cuento literario. Así es como acude a la técnica de Boccaccio e introduce a sus personajes por medio de un encuentro casual. ¿Leería al autor del Decamerón? No lo podemos afirmar; pero sí es lícito suponer que este aficionado a las letras se había leído a Timoneda y sus colecciones de cuentos de tipo italiano de 1564, 1567 y 1569. Por lo tanto, Ercilla va a fingir que encuentra por azar a una doncella que ronda al campo español, exactamente como lo había fingido ocho cantos antes cuando introdujo en su poema a Tegualda.

También, como aquella vez, pregunta a la mujer la causa de su desesperación, y ella le responde con una larga relación en primera persona. Es procedimiento corriente en aquella época, como lo demuestran Montemayor en la Diana (1559), el autor del Lazarillo (1554) y el mismo Ariosto en su Orlando Furioso (más de diez ediciones en español entre 1549 y 1564).

\section{Compárense:}

Mi nombre es Glaura en fuerte hora nacida hija del buen cacique Quilacura. ${ }^{8}$

$\mathrm{y}$

Isabella sono io, che figlia fui del Re mal fortunato da Gallizia."

Muy significativa también es la reacción de Ercilla ante los "libros de caballería" tan en boga en su tiempo:

No las damas, amor, ni gentilezas de caballeros canto enamorados. ${ }^{10}$

de Valdés (Diálogo de la lengua, obra publicada tan sólo en 1737). En aquel tiempo, ni existe verosimilitud ni existe realismo en el sentido actual de estas palabras.

8 Canto XXVIII, est. 7.

9 Canto XIII, est. 4 del Orlando furioso.

I0 Canto I, est. 1. 
Es relación sin corromper sacada de la verdad, cortada a su medida.11

Las mujeres de La Araucana pertenecerán, pues, a este nuestro mundo de violencia y de tragedia, por ficticias que sean sus figuras y sus nombres.

Lo mismo diremos de la actitud del poeta ante las historias de pastores, puestas de moda por Montemayor y sus secuaces.

ni [canto] las muestras, regalos y ternezas

de amorosos afectos y cuidados. ${ }^{12}$

Este género de la novela pastoril, nada utópico, sino muy histórico y real y hasta de llave, le repugnan, como a buen soldado, los juegos afeminados, las cursilerías y las gazmoñerías de los cortesanos a la moda. Sin duda, reconoce Ercilla la "delicadeza" de los grandes maestros Dante, Petrarca y Garcilaso de la Vega, pero condena a sus epígonos. ${ }^{13}$

¡Qué difícil es resistir a la marea creciente de la mala literatura caballeresca o pastoril! Sucumbe y no sucumbe Ercilla. Quisiera sustituir su "ganadería heroica" a los galanteos sosos de los falsos pastores. Véase este retrato "a contra corriente" de Glaura, la rica ganadera:

Era muchacha grande, bien formada,

espaciosa de pecho y relevada,

hermosas manos, brazos bien sacados

......

Mas, ¡ay de mí!, ¡cuánto mejor me fuera

ser una simple y pobre ganadera! 14

Por lo mismo serán sus heroínas esposas de soldados.y

11 Canto I, est. 3.

12 Canto I, est. 1.

13 Dante, Ariosto, Petrarca y el Ibero / Amor los trujo a tanta delgadeza (Canto XV, est. 2). Plagia a Garcilaso en estos dos versos: Armado siempre y siempre en ordenanza, / la pluma ora en la mano ora la lanza (Canto XX, est. 24).

14 Canto XXVIII, est. 4 y 7. 
no amantes de mequetrefes deshonestos. Glaura, salvada de uno de éstos por el que vendrá a ser su esposo, se amedrenta un momento ante una cruel pelea, huye y, como ninfa virgiliana, se esconde en el tronco de un árbol. Pero, al recordar, tiene tanta vergüenza la muchacha por su cobardía, que afrenta todos los peligros en busca de su infeliz y tan amado Cariolán.

No es muy original este errar ansioso de Glaura por los valles y los montes; nos recuerda a Virgilio y a Garcilaso; y también anuncia a Juan de la Cruz. Pero, por una inclinación irresistible, el autor se desliza cada vez del plano pastoril al plano heroico. Así, Tegualda buscaba el cadáver de Crepino en el campo de batalla; así, Glaura, disfrazada de hombre, intenta acercarse al campo español, donde el corazón le dice que vive su marido.

No con menor repugnancia ni con menor dificultad rechaza Ercilla la lección tentadora de las historias legendarias o mitológicas que deleitaban a los jóvenes de su tiempo: Hero y Leandro, Psique, Lucrecia y Tarquino, Pirro y Policena. A Antonio de Villegas le podía perdonar por haber interpolado en su Inventario la noble y generosa historia de don Rodrigo de Narváez (Abindarráez y la hermosa Jarifa), pero no por su traducción de Píramo y Tisbea, fábula mentirosa nada heroica. ${ }^{15}$ También sabemos cómo Ercilla va a tratar en 1589 una ficción del mismo tipo: Dido y Eneas, haciendo de la heroína un modelo de castidad ${ }^{16} \mathrm{y}$ de valor moral.

Sin embargo, no desconoce Ercilla el partido que sacaron de la anagnórisis los bizantinos en sus mal pensadas, pero conmovedoras novelas, Dafnis y Cloe, Teágenes y Cariclea, ${ }^{17}$ etc. Ariosto también supo aprovechar esta técnica, lanzando a sus personajes en sendas y singulares aventuras fantásticas antes de su final reunión. Recuerda Ercilla el caso de Isabella

15 Citamos esta versión por ser de un autor a quien frecuenta Ercilla. Pero esta historia de Ovidio (Met. IV) ya había salido en España bajo la pluma de Castillejo y también en un anónimo romance publicado por Esteban de Nájera en 1530 .

16 Adopta el desenlace de Justino (Filípicas, 1. XVIII), el mismo de la Crónica general. Véase M. R. Lida, "Dido...", R. F. H., IV y V

17 La de más fama es Teágenes $y$ Cariclea, de Heliodoro traducida al franr.s. por Amyot. (Amberes, 1559). 
y Zerbino, episodio interpolado en el Orlando, tan lleno de sugerencias. Al concebir la historia de Glaura y Cariolán va a acudir nuestro poeta a este procedimiento tan eficaz del reconocimiento de los amantes después de peligrosa separación.

Ante todo, conviene decir "no" a la perversidad de los tiempos presentes. Las nuevas letras, piensa Ercilla, deben tomar otro rumbo, otro norte: ni la antigüedad, ni Bizancio, ni Italia, sino España y la religión católica.

Las heroínas de Ercilla no serán, pues, doncellas aventureras, sino "muchachas" casadas y que comparten con sus esposos las peligros de la guerra. $Y$, por araucanas que sean, no se casan con cualquiera. Glaura rechaza las proposiciones deshonestas del deudo de su padre. Ercilla se acuerda aquí del famoso romance de la "destruycion de España". ${ }^{18}$ La Cava se mostraba menos cruel con el rey Rodrigo, amigo también de su padre, cuando la perseguía por sus amores en su palacio de Toledo. Pero nuestro poeta se niega a atribuir a la maldad de una mujer la derrota de los Araucanos, rechazando otra vez la sugerencia de su modelo literario.

Aún va más allá. Da a Glaura una razón muy "tridentina" de no casarse con Fresolano; y es que es primo suyo. ${ }^{19}$

incestuoso, desleal, ingrato,

iO malvado,

corrompedor de la amistad jurada

y ley de parentesco conservada! 20

¿Por qué esa lección de moral cristiana en boca de una Araucana? ¿Por qué ese detalle tan inoportuno del parentesco criminal? ¿Por qué condenar. a muerte, pudiendo salvarle $\mathrm{u}$ olvidarle, al pobre Fresolano? El incesto y su castigo habían

18 Durán, Romancero general.

19 Se prohibió el matrimonio entre deudos hasta el cuarto grado. El tema del amigo traidor lo tratará Cervantes. Recordemos su novelita interpolada en el Quijote: "El curioso impertinente".

20 Canto XXVIII, est. 16. 
de ser obsesiones suyas para que los metiera allí por fuerza. $Y$ esto nos revela tanto su mentalidad personal como las preocupaciones morales del público para quien escribía.

También Ercilla tiene un concepto singular del amor. Las "muchachas bien apuestas" de nuestro poeta aman y se casan tan sólo porque el amor entra en su corazón "por las puertas de la admiración". Ya en la famosa leyenda, doña Jimena se entrega al Cid, Rodrigo Díaz de Vivar, después de vencer éste en "cinco batallas campales". Del mismo modo, Glaura toma por marido a Cariolán cuando este valiente araucano acaba de vencer y matar a dos infames negros que intentaban forzarla. Tanta prisa y tanto ímpetu de parte de una princesa le parece poco moral y poco realista al historiador J. T. Medina, muy de su tiempo. Por cierto, el soldado Ercilla no tenía esos prejuicios neopuritanos. Reserva su aprecio a la mujer que se da y no a la que se abandona.

La castidad es la primera virtud femenina. ${ }^{21}$ (Esta idea es muy de militares). Fiel como Dido es Tegualda, y honrada es Glaura, quien antepone su honor a la miseria y a la vida:
Yo triste no estimaba en nada el perder los vestidos y la vida. Pero el honor y castidad preciada estuvo a punto de ser perdida. ${ }^{22}$

El hecho es importante, pues el honor viene a doblar el otro móvil y resorte tradicional de la acción: este mismo apego a la vida que los acontecimientos a cada momento vienen a echar sobre el tapete. Ercilla acababa de encontrar la roca en que se iba a cimentar la comedia española algunos años después; mas fundaba en ella tan sólo una especie de novela ejemplar, de porvenir mucho menos brillante, y ésta todavía en verso, tentativa sin ecos.

No caigamos en el ridículo de condenarle por esa falta de intuición. Por cierto, tenemos más luces que él sobre lo que

21. En el Canto XVIII, est. 73, nos dará el retrato ideal de la mujer, el de la mujer con quien se había de casar, doña María de Bazán: ...mostrando / en su sosiego discreción madura.

22 Canto XXVIII, est. 24. 
iba a fructificar y lo que no. Admiremos más bien esta su invención transcendente: la dramatización de la intriga en torno a dos ejes, la muerte y el deshonor, siempre inminentes.

No para aquí la deuda del género de la novela al poema épico. Para actuar sobre estos dos resortes inventa Ercilla dos medios en adelante casi imprescindibles: el disfraz y el villano.

Mujeres disfrazadas ya se encuentran en las letras italianas (Boccaccio, Boyardo, Ariosto), ${ }^{23}$ en la Diana, de Montemayor, ${ }^{24}$ en Los Engañados, una adaptación teatral del italiano por Lope de Rueda (1556) ${ }^{25}$ y en los cuentos de Timoneda. Pero van en busca de sus amantes para satisfacer sus malas pasiones, y como el amor les quitó la discreción y el pudor, no tienen nada que perder que ya no estuviera perdido. Son aventureras. Glaura, al contrario, si se disfraza es para escapar al estupro de la soldadesca y reunirse con su esposo.

Sabe el peligro que corre constantemente su honor, ya que la asaltaron con violencia indebida su malvado primo Fresolano y luego otros dos villanos, $\mathrm{y}$, por cierto, negros villanos, villanos negros. Quedamos perplejos ante esta arbitrariedad o genialidad de Ercilla. Entre todos los codiciadores Iujuriosos que abundaban en el ejército escoge a dos negros. ¿Será otro homenaje a la verdad del caso? ${ }^{26}$ Aun si fuera tal, notemos que insiste en el color de sus malvados como si quisiera eximir a los españoles de aquel crimen. Sobre todo, siente como la necesidad de introducir en su episodio a la infamia para que resalte la virtud, a antihéroes para dar más relieve a los héroes. ${ }^{27}$ iCuánto abusaron los futuros novelistas de la ingeniosa fórmula de Ercilla! Los novelistas románticos fundarán en

23 No pudo conocer las novelas (Ilamadas después trágicas: Salamanca, 1589) de Bandello sino en las adaptaciones de Timoneda.

24 Episodio de Felismena y Félix tomado de Bandello.

25 Editada por Timoneda en 1583 después de publicada esta segunda parte de La Araucana.

26 Es muy probable. Literariamente un agresor bastaba. O bien tres agresores si se tratara de ensalzar la hazaña de Cariolán.

27 Ya en la Diana había salvajes que atacaban a tres ninfas. Pero salva a éstos una mujer, Felismena. La situación no puede ser más diferente. 
ella su antagonismo sistemático de las fuerzas del bien y de las fuerzas del mal. De este abuso respondan ellos, que no de su uso el perspicaz Ercilla.

Como presenciaba cada día el choque sangriento de los hugonotes y de los "ligueurs", Bandello, obispo de Agen, tiende a dar a sus intrigas, por italianas que sean, un desenlace sangriento, trágico. Pero Ercilla va mucho más allá en ese sentido, ya que concibe el episodio como una serie de peripecias, o sea la acción como una serie de golpes de teatro. Por ejemplo, Glaura escapa por instantes a las violencias de Fresolano gracias a la intervención inesperada de los españoles, verdaderos Dei ex machina. Luego, se suceden rápidamente acontecimientos nunca previstos y de ningún modo previsibles: Cae en manos de dos negros que la despojan de sus vestidos e intentan abusar de ella. Surge Cariolán. Los vence y los mata. Se casan Glaura y su salvador. Huyen en la selva. Vienen los españoles. El joven esposo desaparece en la pelea que luego se arma. Ella le busca. En vano. Se disfraza de hombre. La descubre el capitán Ercilla. Surge el criado de éste, su yanacona. Y exclama Glaura:

¡O justo Dios!, ¿qué es lo que veo?

¿Eres mi dulce esposo? ;Ay, vida mía!

en mis brazos te tengo y no lo creo.

¿Qué es esto? ¿Estoy soñando o estoy despierta?

¿Ay, que tan grande bien no es cosa cierta! 28

Más trágica no puede ser una novela.

Subrayemos otro rasgo de la pluma de Ercilla. Nunca condena a muerte a sus heroínas, como lo hace con gozo épico con sus héroes. ¿Será tradición literaria? ¿Será su singular ternura por las mujeres? Guacolda y Tegualda desaparecen de nuestra vista después de clamar su desesperación ante la muerte de sus esposos. ${ }^{29}$ Fresia también se marcha, rompiendo su enlace con un esposo indigno de su amor. Y Glaura escapa con su Cariolán de entre la pelea cuando Ercilla les

28 Canto XXVIII, est. 43.

29 Desesperadas quisieran morit. Pero el católico Ercilla no se lo permite 
devuelve la libertad. Es el final feliz de la "tragicomedia" tal como la va a practicar Lope de Vega unos años más tarde. ${ }^{30}$

Pero Ercilla no es literato profesional. La calidad de su poema no reside en el agrado de los adornos librescos, sino en su grandeza moral (y en la nitidez de la expresión). : Magnífico contrasentido el del capitán español al leer el episodio de Isabella y Zerbino, libertados sucesivamente por Orlando ${ }^{31}$ Ariosto atribuía a la casualidad el gesto de su héroe. Ercilla atribuye a la generosidad el gesto del suyo. Es decir, que el español, abandonando la objetividad del narrador, interviene en el relato como personaje y propone al lector su propia escala de valores morales. Muestra cómo un soldado sabe deponer el rigor de las armas en medio del combate para satisfacer lo que debe a su propia alma, afirmando su integridad.

Otra obrita, encantadora, por cierto, le sirvió ahí de guía y de piedra de toque: "la historia de Abindarráez y la hermosa Jarifa" interpolada en el Inventario de Antonio de Villegas en 1551 y publicada con él en $1565 .^{32}$ Allí, el capitán español Rodrigo de Narváez liberta a un noble moro por espacio de tres días, lo bastante para que éste pueda recoger a su amada Jarifa de casa de su padre, que era reacio a estos amores. Al volver los novios a su poder, don Rodrigo se enternece y les devuelve incondicionalmente la libertad, que lo propio de un caballero "no es robar damas, sino servirlas y honrarlas".

A Ercilla le parece disparatada y fofa esa moraleja final de la novelita. Un soldado de verdad no es caballero andante y no gusta de debilidades sentimentales ni en sí ni en

y detiene su cruel mano, "su rabiosa gana de la muerte". Según él; es "gentílico intento y desvario" (Canto XXI, est. 10 y 11).

30 Ercilla tiene una conciencia clara de la virtud literaria del "happy ending": "Visto de Glaura el mísero intento / en felice suceso rematado" (Canto XXVIII, est. 44).

31 Orlando furioso, XIII y XXIII.

32 Interpolada también en la Diana a partir de la edición de 1561. Pero circulaba también en manuscritos y poco tiempo después en una edición suelta. (Medina, 1565). 
los demás. Eso es literatura. Ercilla liberta a Cariolán por ser éste su fiel yanacona, cuya vida peligraría más que la de nadie en la lucha que se entabla entre españoles y rebeldes araucanos. Y a Glaura la liberta por la admiración que ha suscitado en él su alta calidad de mujer casta, fiel y heroica. Por lo tanto, su acto de gracia viene a ser recompensa de la virtud y se funda en un criterio propiamente moral.

\section{Amigos, adiós, y lo que puedo que es daros libertad yo os lo concedo.}

Este desenlace es perfecto coronamiento estético y ético del episodio de Glaura. Pero ahí no se para su vitrud. Pues define con la mayor precisión una actitud y un valor social hasta aquel tiempo informulados, si bien presentes en las profundidades del alma española. Ercilla se propone $-\mathrm{y}$ consigue-aclarar y expresar sentimientos colectivos confusos. $Y$ surge de su pluma un esquema de comportamiento que va a ser una de las directrices de su nación ${ }^{33}$ en los años, en los siglos por venir. Al hacer esto rompe con la modalidad frívola de las letras italianas o italianizantes: No basta deleitar, hay que aprovechar..$^{34}$ También rompe con la falsa objetividad de los novelistas profesionales. Es a la vez narrador y personaje. Y escribe para purgar tanto sus pasiones como las de su público. ${ }^{35}$ Todo su poema y este episodio de Glaura en particular los consagra a enaltecer la entereza del hombre nunca corrompida en el servicio de Venus ni en el servicio de Marte.

Charles V. Aubrun. University of Texas, Sorbonne. París.

$33 \mathrm{Y}$ por herencia, de las naciones hispanoamericanas, por cierto.

34 Observamos la misma reacción en Cervantes, también soldado escritor, en sus Novelas Ejemplares y en su Quijote (Primera parte). Lope también rompe con la tradición y la rutina en su Arte nuevo y fija para años y acaso siglos el estilo peculiar del galanteo español.

35 Véase López Pinciano, op. cit., muy consciente de este tercer papel de las letras, sobre todo en España: la catarsis. "Tres provechos traen estas artes .... el uno ei alterar y quietar las pasiones del alma a sus tiempos convenientes, el segundo meis rar las costumbres, el tercero... el entretenimiento". 
